\title{
Golf course revenue management: A study of tee time intervals
}

\author{
Sheryl E. Kimes \\ School of Hotel Administration \\ Cornell University \\ Lee W. Schruben \\ Industrial Engineering and Operations Research \\ University of California at Berkeley
}

KEYWORDS: revenue management, golf, simulation

\begin{abstract}
Golf courses have two strategic levers, round duration control and demand-based pricing that they can deploy in a revenue management programme. Before embarking on a revenue management programme, golf courses must first clearly define their capacity. This study uses simulation to study the most controllable factor of capacity: the tee time interval. Intuitively, reducing the interval between parties will lead to an increase in revenue; however, this paper shows that interval reductions may actually lead to decreased revenue.
\end{abstract}

Research in revenue management (RM) has previously addressed the theoretical and practical problems facing airlines and hotels, among other industries, but has given little attention to the golf course industry (Kimes, 1989; Weatherford and Bodily, 1992). The golf course business is similar enough to hotel and airline operations that golf courses should be able to apply RM principles (Kimes, 2000).

Industries using RM generally measure their performance by calculating their revenue (or contribution) per available time-based inventory unit. For example, hotels calculate their revenue per available room-night (RevPAR), airlines determine their revenue per available seat-mile (RevPAS), and restaurants rely on revenue per available seat-hour (RevPASH). Based on this logic, golf courses should measure their revenue per available tee-time (RevPATT), but the 
definition of availability is not as precise as in other industries. The number of available tee times is affected by both controllable and uncontrollable factors. Controllable factors include the length of a round of golf, the dispatching rule used, maintenance and the tee time interval. Uncontrollable factors include the number of hours of daylight and weather. Unless golf course operators have a clear definition of their capacity, they will not be able to measure the performance of their RM systems.

This paper focuses on the most easily controllable factor affecting course capacity: the tee time interval. A dynamic simulation model was developed, which can be used to quantify the trade-offs in determining an appropriate tee time interval. Intuitively, reducing the time interval between parties might lead to an increase in throughput and revenue; however, tee time interval reductions may amplify the effects of the variations in pace of play and result in a reduced RevPATT. 


\section{REVENUE MANAGEMENT}

Revenue management is the application of information systems and pricing strategies to allocate the right capacity to the right customer at the right place at the right time (Smith et al., 1992). In practice, RM has meant setting prices according to predicted demand levels so that price-sensitive customers who are willing to purchase at off-peak times can do so at favourable prices, while price-insensitive customers who want to purchase at peak times will be able to do so. The application of RM has been most effective when it has been applied to operations that have the following characteristics: limited capacity, predictable demand, perishable inventory, varying customer price sensitivity, appropriate cost and pricing structure, and demand that is variable and uncertain (Kimes, 1989; Cross, 1997) Those attributes are generally found in some form or another in the golf course industry (Kimes, 2000).

Golf courses possess many of the characteristics that call for RM, but there is little evidence of managers using a strategic approach for deploying the demand management mechanisms at hand.

Although some golf courses use demand based pricing (Stabile, 2000) and others have adopted pace of play systems (United States Golf Association, 2002), very few courses have adopted a unified and systematic approach to RM. A successful RM strategy is predicated on effective control of customer demand. Two strategic levers for golf course RM are available: duration management and demand-based pricing (Kimes and Chase, 1998).

Different industries are subject to different combinations of duration control and variable pricing (see Figure 1). Industries traditionally associated with RM (hotels, airlines, car-rental firms and cruise lines) are able to apply variable pricing for a product that has a specified or predictable duration (Quadrant 2). Cinemas, performing-arts centres, arenas and convention centres charge a fixed price for a product of predictable duration (Quadrant 1), while golf courses, restaurants and most Internet service providers charge a fixed price but face a relatively unpredictable duration of customer use (Quadrant 3).

Some health-care services charge variable prices (e.g. HMOs, Medicare versus private pay), and some may try to control the duration of use (Quadrant 4). The lines dividing the quadrants are broken because, in reality, no fixed demarcation point exists between quadrants. Thus, an industry (such as golf) may have attributes from more than one quadrant. 


\begin{tabular}{|c|c|c|c|}
\hline & & \multicolumn{2}{|c|}{ Price } \\
\hline & & Fixed & Variable \\
\hline \multirow{3}{*}{ 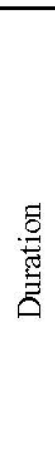 } & Predictable & Quadrant 1: & Quadrant 2: \\
\hline & & $\begin{array}{c}\text { Theatres } \\
\text { Stadiums/Arenas } \\
\text { Convention Centres }\end{array}$ & $\begin{array}{l}\text { Hotels } \\
\text { Airlines } \\
\text { Rental Cars } \\
\text { Cruise Lines }\end{array}$ \\
\hline & Unpredictable & $\begin{array}{c}\text { Quadrant 3: } \\
\text { Restaurants } \\
\text { Golf Courses } \\
\text { Internet Service Providers }\end{array}$ & $\begin{array}{c}\text { Quadrant 4: } \\
\text { Health Services }\end{array}$ \\
\hline
\end{tabular}

Golf course operators can use round duration control and variable pricing to help maximise their revenue per available tee time. Round duration can be managed by reducing the uncertainty of arrival, by reducing the uncertainty of duration or by reducing the tee time interval. Variable pricing can be implemented by developing optimal prices and by setting rules to determine who is charged which price. These techniques have been thoroughly discussed in an earlier paper (Kimes, 2000).

Regardless of the RM tools selected, a golf course must first determine its capacity. As mentioned above, the definition of golf course capacity is not straightforward, and is strongly affected by the tee time interval used, the speed of play, the hours of operation, the course design and management practices. This paper uses simulation to study the capacity and revenue impact of a reduced tee time interval. All other factors (speed of play, hours of operations, course design and management practice) were held constant.

Reducing the tee time interval may increase capacity and revenue. Intuitively, if the amount of time between parties can be reduced, more customers can be accommodated and revenues could be increased. Consider a golf course that is open for 10 hours. If the golf course reduces a 10- minute tee time interval down to an 8- minute tee time interval, the capacity of the course (measured in starts) will increase by 25 per cent. This tactic will not offend a departing customer and should please the customers who are waiting to play, but may cause an increase in course congestion at bottleneck holes due to variations in the pace of play. Golf courses using 8- 
Figure 2: Average time by hole

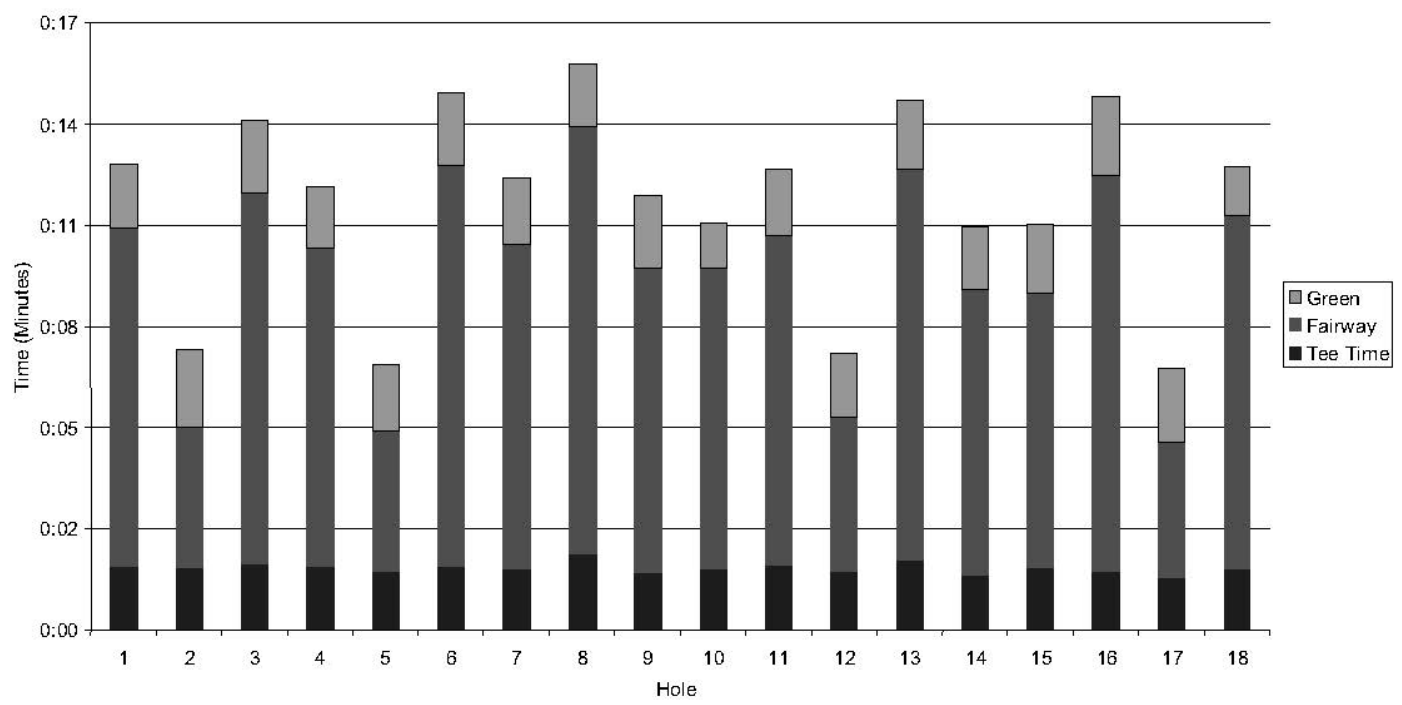

and 9- minute tee time intervals report no difficulty with customers honouring the sometimesunusual starting times.

Unfortunately, arrival and duration uncertainty may confound the revenue potential from a reduced tee time interval. If players arrive late for their tee time, if a party shows up with fewer people than expected (shrinkage) or if a party does not show up at all, the potential benefits of tee time interval are reduced. Furthermore, without knowing the capacity of the course, it is not possible to set a reasonable tee time. In addition, if the playing time of customers within a party varies or if playing time of parties on the course has high variability, bottlenecks can occur and the theoretical capacity limits may be reduced.

Most golf courses schedule parties at 8-12-minute intervals. Some alternate between one interval and another (for example, alternate between 8- and 9- minute tee time intervals). Some resorts charge price premiums for courses with a long tee time interval and offer discounts for courses with a shorter tee time interval. The question of what the optimal tee time interval is has not yet been addressed and is the focus of this research.

\section{THE STUDY}

To parameterise the simulation model, a time study on 90 players was conducted (Delgado-Muerza, 2000). The tee-off time, the fairway time and the green time for each player 
were recorded for each of the 18 holes. Average and standard deviations for each hole for the tee-off time, fairway time and green time were calculated (see Figure 2).

An event-based simulation model was built to address the questions (Figure 3). The time study data in Figure 2 were used to parameterise the model. Since this study is illustrative and the data specific to a particular course, probability distributions (truncated normal) were fit to the various times. Since the variances of play times observed in the time study were small, these will have little impact on the qualitative results of the study. Of course, the data will differ for individual courses, and distribution fitting would be an important part of the study. Since the purpose of the research was to study the impact of reduced tee time intervals, course design, hours of operation, playing time and management policies were held constant. Experiments were then run to compute performance statistics for various tee time intervals.

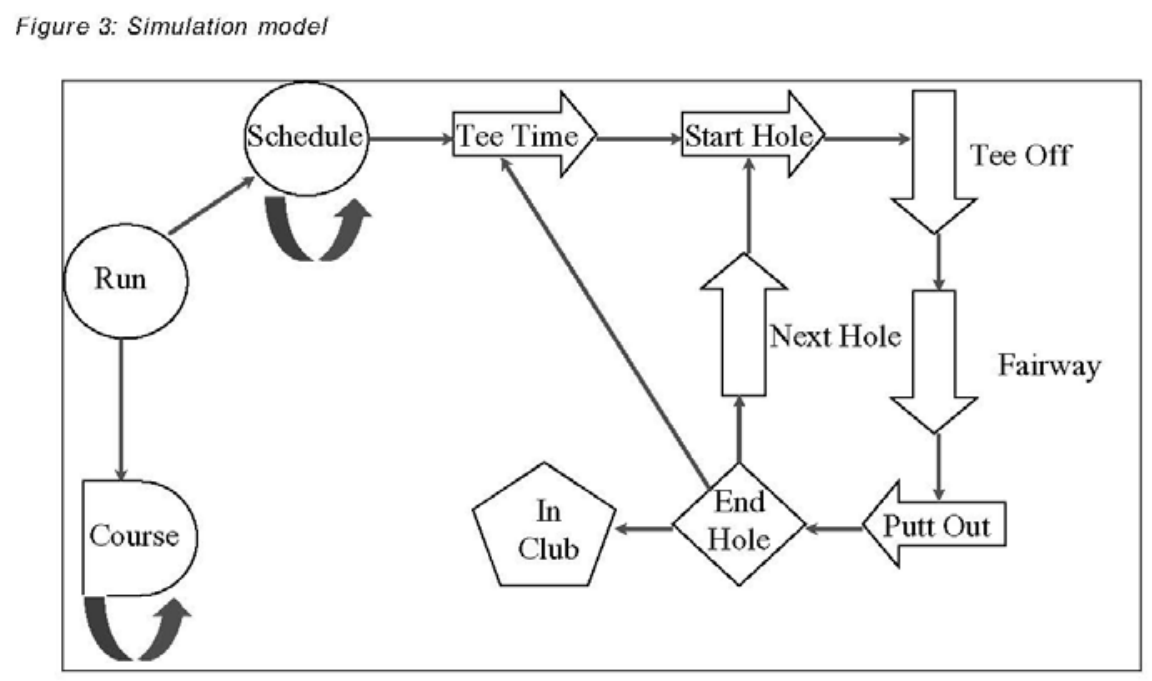

In this model, players were scheduled at designated tee time intervals and were allowed to tee-off at hole 1 if there were no more than two parties currently playing the hole. If there were more than two parties, the new party was required to wait in the clubhouse.

Once a party teed off on the first hole, they moved to the fairway, then on to the green. When all players in the party had sunk their ball, the party moved on to the next hole. Again, if there were more than two parties playing the next hole, the arriving party could not start until one of the other parties completed the hole. The party would then proceed through the course until completing the 18th hole. 


\section{Model parameters}

The simulation had four input parameters: time of operation, average lateness, standard deviation of lateness, and tee time interval. For this study, the focus was on the impact of different tee time intervals. The simulated course was open for 10 hours, meaning that the latest tee time could be no later than 10 hours after the course opening (for example, a course that would schedule tee times between 6 am and $4 \mathrm{pm}$ ). On average, customers were assumed to arrive on time (mean lateness= 0 minutes) with a standard deviation of lateness of 1 minute. Separate experiments were conducted for eight different tee time intervals (8, 9, 10, 11, 12, 13 and 14 minutes). A hundred days of operation were simulated for each tee time interval. The simulation model was fast enough that sufficient replications were made to make the variance of the performance measures collected (all averages) insignificant.

\section{Variables measured}

Three variables were traced for each party: throughput time, play time and wait time. Throughput time was defined as the time from when the party was scheduled to begin play to when they had completed the last hole. Play time was measured as the difference between when the party actually teed off on the first hole and when they had completed hole 18. Wait time was the difference between throughput time and play time and represented the amount of time players had to wait before beginning play. Three other variables, the clear time, the maximum clubhouse queue and the number of parties, were traced for each day of operation (10-hour period). The clear time was the time from when the course opened until the last party had completed play. The maximum clubhouse queue was the maximum number of parties in the clubhouse who could not begin play because of bottlenecks on the first hole. The number of parties represented the number of parties who began play during the 10-hour open period.

\section{RESULTS}


In the simulation, a simple dynamic bar graph was used to track the progress through the course. The number of parties currently at the hole and the maximum number of parties ever at the hole were both tracked and could be viewed over time. For example, at $\mathrm{t}=300$ minutes (after 5 hours) (Figure 4), there were two parties at holes 1-3, none at hole 4, one at hole 5, two at holes 6 and 7, one at hole 8, none at hole 9, three at hole 10, one at hole 11, none at holes 12 and 13, two at hole 14 , one at hole 15 , two at hole 16 , and one at hole 17 and 18 . The maximum number of parties ever at holes 1, 2, 4, 7, 8, 9, 11, 12, 13, 14, 16 and 17 was three; at holes 3, 4, 6, 15 and 18 it was two, and at hole 10 it was four. Hole 10 was located directly after the midcourse break, and many parties stopped for a snack and a drink before beginning hole 10 .

Figure 4: Course activity: 300 minutes

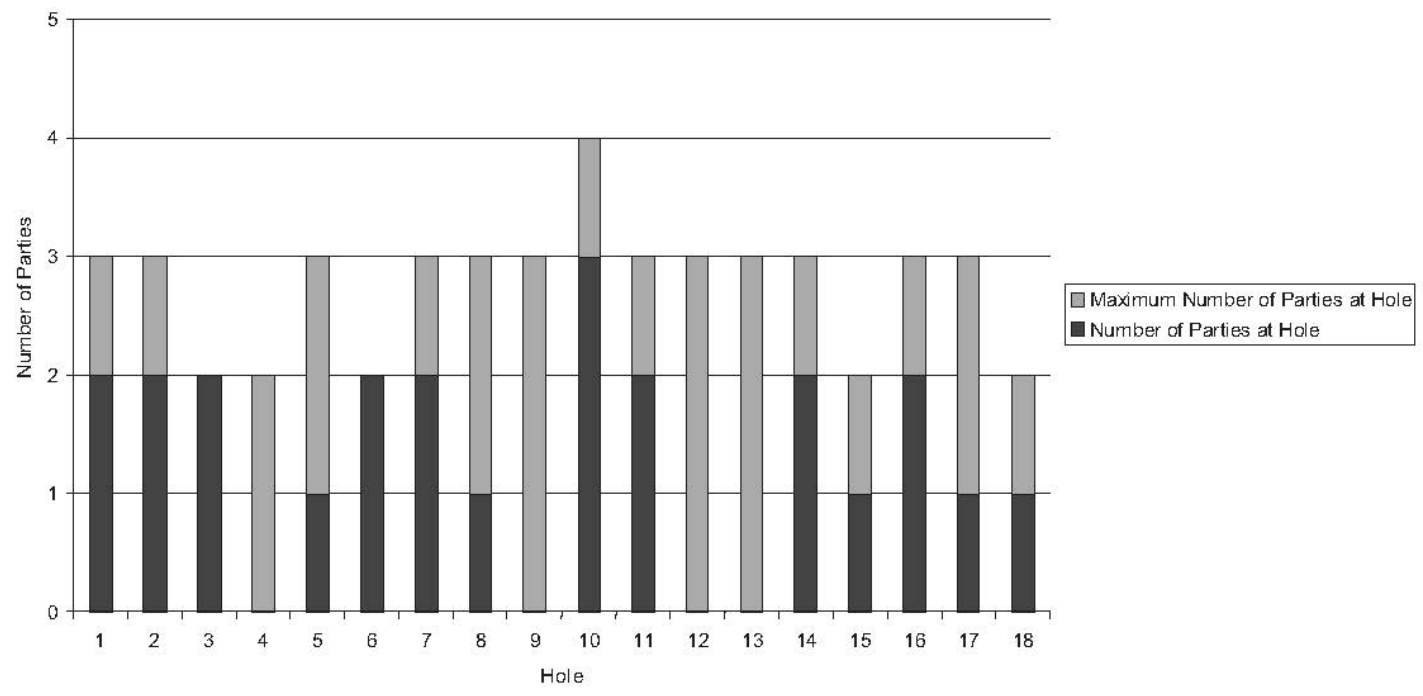

After 400 minutes, the parties had moved on (Figure 5). Holes 1, 2, 3, 4, 7, 12, 17 and 18 each had one party; holes 6, 9, 11 and 15 had two parties; and hole 10 had three parties. The maximum number of players ever at a hole had increased, with holes 1-8, 12-13 and 16-18 each having a maximum of three parties, and holes 9-11 and 14-15 a maximum of four parties. 


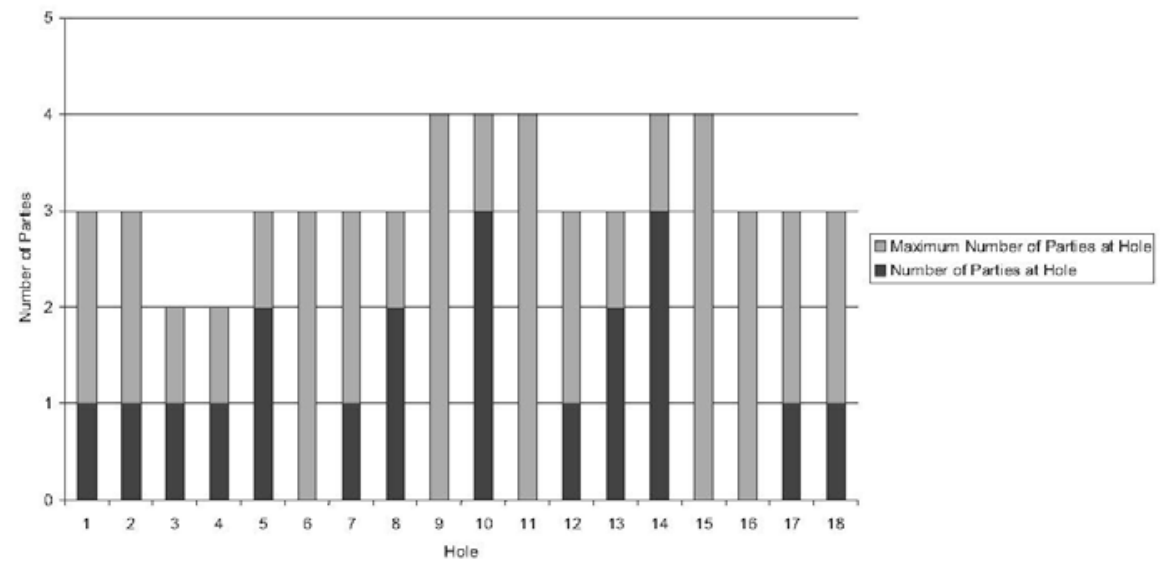

\section{Play time, throughput time and wait time}

Theoretically, the bottleneck hole in this course was hole 8, with an average party play time of 16 minutes and 7 seconds. Elementary queuing theory principles indicate that, since up to two parties are allowed to play a hole at the same time, there cannot be a tee time interval of less than about 8 minutes without causing the queue to become unstable, with parties arriving at a faster rate than they can play this hole. The rate at which hole 8 can accommodate parties (about one new party every 8 minutes) has to be lower than the rate at which they are allowed to tee off. The average play time (the time from when the party actually teed off on the first hole until they had completed hole 18) was between 235 and 239 minutes regardless of the tee time interval (Figure 6). This is due to the filtering effect of holes before the 8th hole in preventing the eventual congestion at this bottleneck hole - much like a metering light on a motorway. The throughput time (the time from when the party was scheduled to begin play to when they had completed the last hole) was approximately 248 minutes for tee time intervals of 12-14 minutes, but increased at lower tee time intervals. At a tee time interval of 11 minutes, the throughput time increased to 260 minutes; at 9 minutes, 293 minutes; and at 7 minutes, increased sharply to 425 minutes as the queue became unstable. The wait time increased dramatically at tee time intervals less than 9 minutes. 
Figure 6: Impact of tee time interval on play time and throughput time

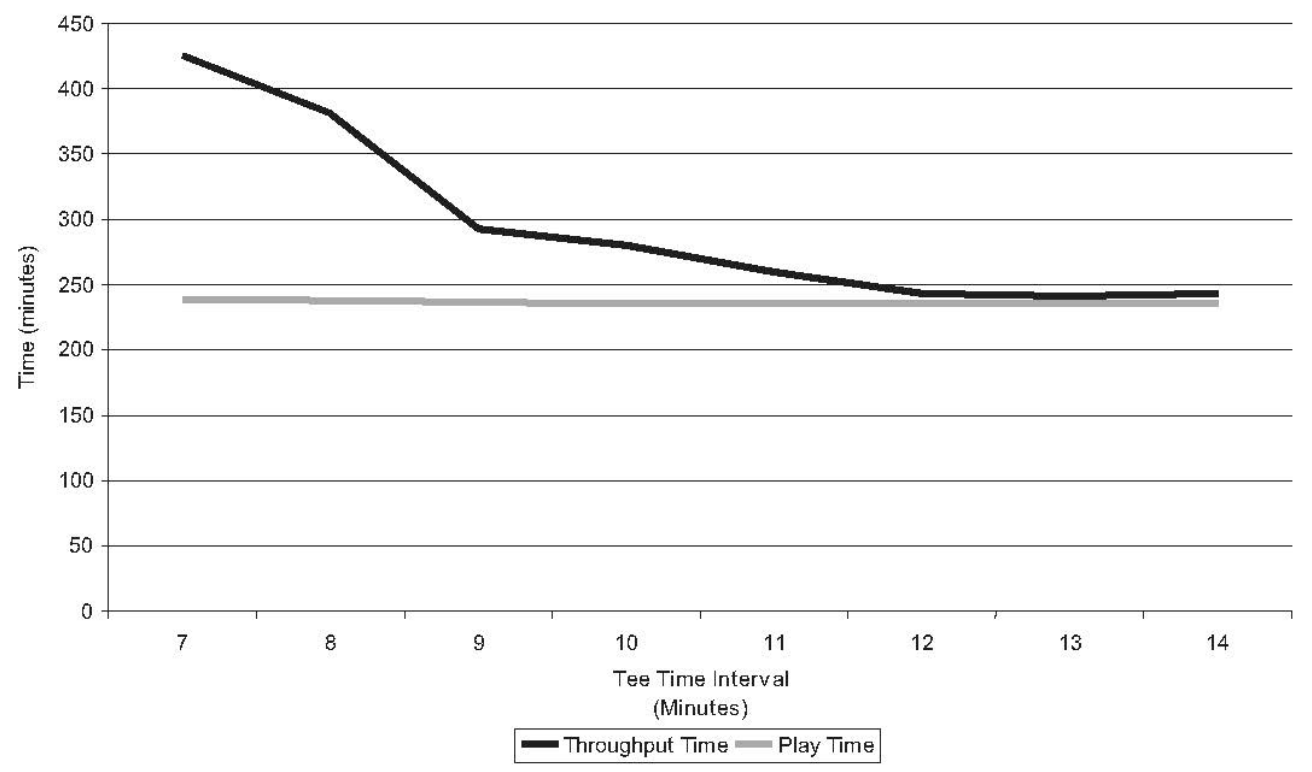

\section{Clear time}

The total time to clear all players was approximately 840 minutes (14 hours) for tee time intervals of 11-14 minutes, but increased sharply for tee time intervals of less than 9 minutes (Figure 7). When the tee time interval was 7 minutes, it took over 1,200 minutes (20 hours) for all parties to complete play — clearly infeasible. This again indicates that the system has become unstable when more parties were allowed to start at a faster rate than could be handled at the bottleneck hole. 
Figure 7: Clear time by tee time interval

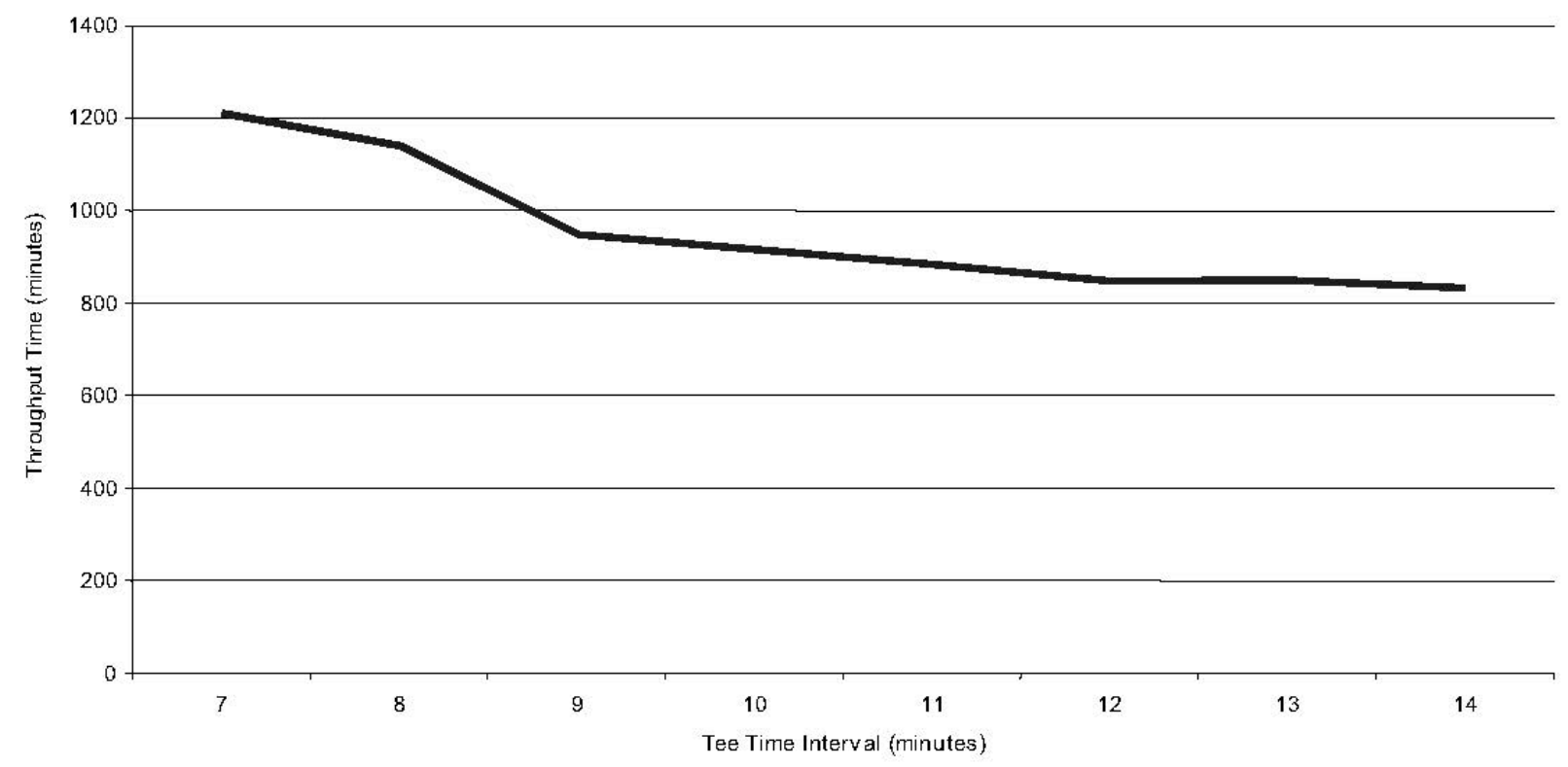

\section{Clubhouse queue}

Not surprisingly, the queue of parties waiting to begin play increased as the tee time interval decreased (Figure 8). At tee times of 12 minutes or more, only one or two parties on average were forced to wait to begin play. At an 11-minute tee time interval, the queue increased to four parties; at 10 minutes, eight parties; at 9 minutes, nine parties; at 8 minutes, 25 parties; and at 7 minutes, 32 parties. Clearly, tee time intervals of less than 9 minutes would not work well at the subject course.

\section{Parties served}

The theoretical capacity (the number of parties scheduled) does not necessarily match the realised capacity (the number of parties served) because of variations in playing time and the number of hours of daylight. The realised capacity (the number of parties who teed off within 10 hours) varied from 43 parties with a 14-minute tee time interval to 45 parties with a 13- minute tee time interval and remained fairly steady at about 51 parties for all lower tee time intervals (Figure 9). Even though the theoretical capacity with a 7- minute tee time interval was over 80, only51 parties were able to begin play before 10 hours of opening. Even though more players 
can be scheduled with a shorter tee time interval, the variability in playing time prevents this schedule from being executed successfully.

\section{FUTURE RESEARCH AND CONCLUSIONS}

Based on a study such as this, a golf course manager can determine an optimal tee time interval. It could specify the maximum amount of time it would want customers to wait and then derive the minimum tee time interval that would provide that level of service. At the golf course studied, management thought that the maximum revenue constrained by customer satisfaction probably occurs around an 11-minute tee time interval. The number of parties accommodated (and hence the revenue) was about the same for both 10- and 11- minute tee time intervals, but the wait for the 11-minute tee time interval was significantly shorter, resulting in higher customer satisfaction. This study indicates an important point: a course cannot operate too near its theoretical capacity when there is variability in pace of play or arrival times.

This study concentrated solely on manipulating the tee time interval. Future research will address the revenue and throughput impact of reductions in playing time, changes in management policies (i.e. required use of carts) and changes in course design.

The capacity of the golf course must be estimated before any successful RM strategy can be implemented. This paper has illustrated how a dynamic computer simulation model can be

Figure 8: Maximum clubhouse queue by tee time interval

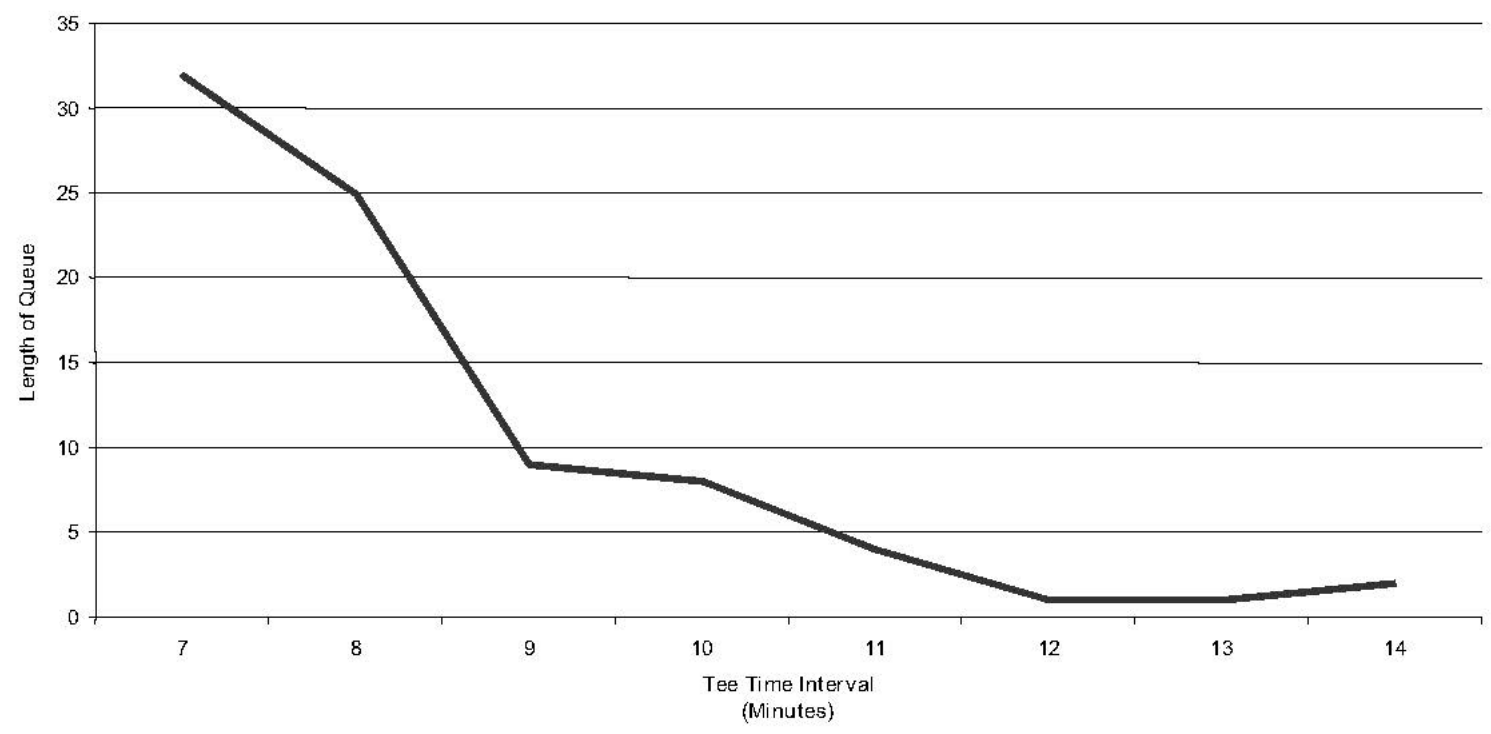


used to determine an appropriate tee time interval for a golf course by accounting for such factors as variability in demand and pace of play. The practical capacity of a course can be considerably lower than the theoretical course capacity one might compute using elementary queuing theory. Simulation experiments can also be used to study the impact of such changes in policy as changing to an optimal party size, allowing short-loop play, permitting split-day scheduling, and dynamic routing - determining the sequence in which a party plays the holes to minimise congestion and thus maximise throughput and revenues while maintaining a high level of customer satisfaction. 


\section{REFERENCES}

Cross, R. G. (1997) Revenue Management: Hard- Core Tactics for Market Domination, Broadway Books, New York.

Delgado-Muerza, A. (2000) Golf revenue management: an application to the Robert Trent Jones Golf Course at Cornell University, unpublished monograph, Cornell University School of Hotel Administration, Ithaca, NY.

Kimes, S. E. (1989) 'Yield management: a tool for capacity-constrained service firms', Journal of Operations Management, 8, 4, 348-363.

Kimes, S. E. (2000) 'Revenue management on the links', Cornell Hotel and Restaurant Administration Quarterly, 41, 1, 120-127.

Kimes, S. E. and Chase, R. B. (1998) 'The strategic levers of yield management', Journal of Service Research, 1, 2, $\quad$ 156-166.

Smith, B. C., Leimkuhler, J. F. and Darrow, R. M. (1992) 'Yield management at American Airlines', Interfaces, 22, 1, 8-31.

Stabile, T. (2000) 'Greens fees balance act', Crittenden Golf, July, 18-24.

United States Golf Association (2002) USGA Golf Rating Manual, United States Golf Association, Far Hills, NJ.

Weatherford, L. R. and Bodily, S. E. (1992) 'A taxonomy and research overview of perishableasset revenue management: yield management, overbooking, and pricing', Operations Research, 40, 831-843. 